\title{
Anabases
}

ANABASES Traditions et réceptions de l'Antiquité

$8 \mid 2008$

Varia

\section{Martin M. WINKLER (éd.), Spartacus: film and history}

\section{Geneviève Hoffmann}

\section{OpenEdition}

\section{Journals}

Édition électronique

URL : http://journals.openedition.org/anabases/278

DOI : 10.4000/anabases. 278

ISSN : 2256-9421

Éditeur

E.R.A.S.M.E.

\section{Édition imprimée}

Date de publication : 1 octobre 2008

Pagination : 315-317

ISSN : 1774-4296

\section{Référence électronique}

Geneviève Hoffmann, « Martin M. winkLer (éd.), Spartacus: film and history », Anabases [En ligne], 8| 2008, mis en ligne le 01 juillet 2011, consulté le 22 septembre 2020. URL : http://

journals.openedition.org/anabases/278; DOI : https://doi.org/10.4000/anabases.278

Ce document a été généré automatiquement le 22 septembre 2020.

(c) Anabases 


\title{
Martin M. WINKLER (éd.), Spartacus: film and history
}

\author{
Geneviève Hoffmann
}

\section{RÉFÉRENCE}

Martin M. WINKLER (éd.), Spartacus: film and history, Malden, Blackwell Publishing Ltd, 2007, 267 p.

19,99 livres / ISBN 978-1-4051-3181-0.

1 Voilà près de cinquante ans sortait sur les écrans Spartacus, film de Stanley Kubrick, encore jeune cinéaste (il n'avait pas 32 ans), dont le principal acteur était aussi le producteur en la personne de Kirk Douglas. Ce film historique au budget important pour l'époque, plusieurs fois récompensé, semblait en phase avec la société américaine qui sortait à peine du maccarthysme, de ces années de "chasse aux sorcières " qui n'épargnèrent pas l'industrie du cinéma.

2 Sur le modèle de l'ouvrage qu'il a publié en 2004 sous le titre : Gladiator : film and history, Matin M. Winkler (MMW) a réuni dans cet essai onze contributions de spécialistes de cinéma et de la littérature latine. Fort d'une méthode déjà éprouvée, il défend dans sa présentation (p. 1-13) l'intérêt d'une étude littéraire, pour ainsi dire philologique, de la production cinématographique, par une formule lapidaire : «Films are visual texts» (p. 9). Le film Spartacus a créé un mythe moderne à partir du roman d'Howard Fast, inspiré par une tradition historique et littéraire. C'est cette genèse qui est au cœur de l'entreprise suscitée par MMW.

3 L'essai est construit en fonction du film. Les trois premiers chapitres auxquels il faut ajouter les reprises du livre programmatique de la mise en scène (chapitres 5 et 6), sont dévolus à l'élaboration scripturale et scénique. D'un intérêt tout particulier, sont les analyses proposées par le critique du cinéma Duncan L. Cooper (chapitres 1 et 2), qui mettent en lumière le rôle fondamental joué par Dalton Trumbo. Faisant partie de ceux que l'on a appelés « les Dix d'Hollywood », inscrit sur la liste noire pour ses sympathies 
communistes - ce qui lui interdisait de travailler pour le cinéma -, ce romancier déjà célèbre ne sortit officiellement de cette proscription qu'en 1960 grâce à Otto Preminger pour qui il avait écrit Exodus la même année que Spartacus. C'est que la confection du film n'a pas été sans mal. Kubrick qui succéda à Anthony Man en désaccord avec Kirk Douglas, ne se reconnut jamais totalement dans son œuvre - celle qu'il aimait le moins -, d'autant que la version projetée en 1960 était tronquée et ne fut restaurée qu'en 1991 dans une forme qui n'était pas totalement fidèle à l'original. Howard Fast, auteur du roman à l'origine de l'entreprise de Douglas, se jugeait en partie trahi par le scénario écrit par D. Trumbo qui lui-même se plaignait amèrement de ne pas avoir pu contrôler toutes les scènes du film, certaines ayant été reprises à la demande de Kirk Douglas par Kubrick lui-même en collaboration avec Howard Fast. Ce sont ces étapes, les controverses sur le sens historique de la révolte servile et les différentes versions du film, que les deux études de D.L. Cooper ont mises en perspective. La contribution de Frederick Ahl, spécialiste de littératures comparées, démontre comment Dalton Trumbo, militant antimilitariste notoire - son roman Johnny Got his Gun date de 1939 devint lui-même l'otage de l'idéologie dominante en faveur du concept de guerre juste (p. 65-86), développé aussi bien dans Exodus que Spartacus.

4 L'autre dimension explorée porte sur la vraisemblance et le respect des évidences historiques. L'étude de l'historien Allen M. Ward (chapitre 4, p.87-111) est particulièrement savoureuse quand dans un tableau équilibré, il dénonce avec humour les incohérences du film - de la reproduction du Sénat ("one major gaffe », p. 90) au nom latin Varinia de la femme de Spartacus, alors qu'elle est comme lui d'origine thrace. W. Jeffrey Tatum, spécialiste de littérature latine, décompose avec brio l'image de Marcus Licinius Crassus, construite par opposition à celle de Spartacus, y compris pour sa sexualité. Cette image de Crassus n'est en rien conforme à celle donnée par les sources (p.128-143). Dans le même esprit, Michael Parenti (chapitre 8, p. 144-153) nous offre un bilan cette fois-ci uniquement historique sur les raisons de l'échec de Spartacus. Ces trois études révèlent les partis pris du film dans la construction dialectique des personnages et la perspective imposée à la révolte servile.

Le troisième et dernier thème nous ramène à la filmographie. Si Francisco Javier Tovar Paz (chapitre 10, p. 189-197) voit dans le film l'expression de l'idéal stoïcien, MMW consacre deux longs développements (chapitres 9 et 11) aux valeurs véhiculées par le film en adéquation avec celles de la société américaine, et à la place prise par l'Antiquité dans l'industrie d'Hollywood. Il souligne, preuves à l'appui, comment les Universitaires ont contribué à réévaluer la production cinématographique qui occupe désormais une place essentielle dans l'histoire culturelle.

Illustré par un cahier de photos, agrémenté de nombreuses citations extraites d'interviews, cet essai ne réduit pas la multiplicité des interprétations que le film suggère sur les thèmes du pouvoir et de la guerre. Au contraire, il les approfondit en révélant la complexité des enjeux. On peut seulement regretter que l'aspect technique, les moyens déployés et l'écriture filmique elle-même ne soient pas davantage explorés, car de même que l'iconographie n'est pas seulement l'illustration d'un texte littéraire, un film n'est pas seulement « un texte visuel ». Il est une source qui crée de la fiction à partir d'une image du réel avec des procédés et des buts qui doivent être pris en compte. Quoi qu'il en soit, le héros Spartacus de Douglas, de Trumbo et de Kubrick, loin d'être un personnage simpliste, gagne en humanité à la lecture de cet essai, par la diversité de ses facettes. Bien sûr, ce n'est pas ce qu'il fut qui surgit sous nos yeux - il 
vaut mieux relire les Anciens -, mais ce qu'il devait être pour répondre à l'attente d'Hollywood et des spectateurs américains en 1960. Entre le refus de l'esclavage et l'espoir messianique, entre la volonté de liberté et le courage du stoïcisme, entre l'austérité puritaine et l'affirmation de l'anti-racisme, Spartacus a permis bien des identifications, une des plus émouvantes étant celle de Kirk Douglas, fils d'immigrants juifs illettrés (p. 167). Cet essai consacre donc une interprétation contemporaine des défis de la société américaine des années $60 \mathrm{du}$ siècle dernier, tels qu'ils se lisent sur le grand écran. Il contribue à donner à l'industrie du cinéma une place légitime dans l'histoire des idées.

\section{AUTEURS}

\section{GENEVIĖVE HOFFMANN}

Université de Picardie Jules Verne genevieve.hoffmann@wanadoo.fr 